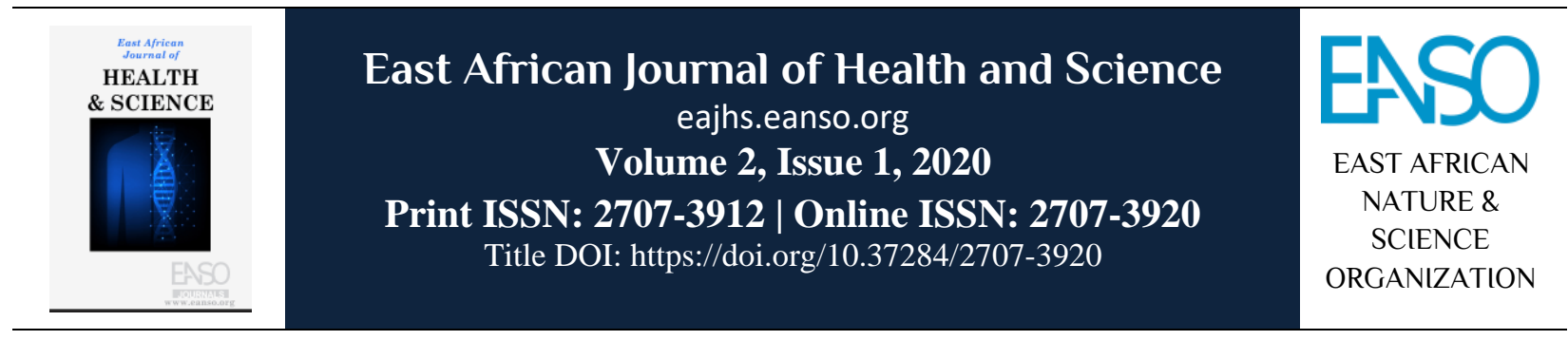

Original Article

\title{
Effects of Anticipated Stigma and Discrimination on Self-Disclosure of HIV Seropositive Status among People Living with HIV and AIDS in Kenya
}

\author{
Lucy W. Ngige, $P h D^{1 *} \&$ Phoebe D. Ndayala, PhD ${ }^{2}$ \\ ${ }^{1}$ Kenyatta University, P. O. Box 43844 - 00100, Nairobi, Kenya; ORCID: https://orcid.org/0000-0003-1750-1496. \\ ${ }^{2}$ Kenyatta University, P. O. Box 43844 - 00100, Nairobi, Kenya; ORCID: https://orcid.org/0000-0002-2406-8989. \\ *Author for correspondence email: ngigelucy@gmail.com.
}

Article DOI: https://doi.org/10.37284/eajhs.2.1.211

\section{Date Published: ABSTRACT}

11 September 2020 The purpose of the study was to establish whether anticipated stigma and discrimination from intimate partners and social support networks such as family,

Keywords: friends, neighbours, community, religious affiliates and workmates predicted the

HIV and AIDS,

Seropositive,

Serostatus,

Self-Disclosure,

Stigma,

Discrimination, likelihood of self-disclosure of HIV seropositive status by People Living with HIV and AIDS (PLWHA) in Kenya. A survey was conducted among a random sample of 232 adult Persons Living with HIV and AIDS in Nairobi, Kenya. Data was collected using interviews and focus group discussions. The results revealed that $50.5 \%$ had disclosed their HIV seropositive status, while $49.5 \%$ had not. The results of regression analysis revealed that anticipated stigma and discrimination by Kenya. intimate partners and social support networks were statistically significant negative predictors of self-disclosure of HIV seropositive status among PLWHA as evidenced by the Adjusted Odds Ratio (AOR < 1.000). The negative predictors included anticipated intimate partner violence $(\mathrm{AOR}=0.635 ; \mathrm{p}=0.016$ ), abandonment by the family $(\mathrm{AOR}=0.410 ; \mathrm{p}=0.002)$, isolation by friends ( $\mathrm{AOR}=0.136 ; \mathrm{p}=0.001)$, exclusion from social functions $(\mathrm{AOR}=0.365 ; \mathrm{p}=0.002)$, exclusion from access to community amenities ( $A O R=0.416 ; p=0.032)$, exclusion by the religious group ( $\mathrm{AOR}=0.446 ; \mathrm{p}=0.032$ ), and dismissal from the workplace $(\mathrm{AOR}=0.266 ; \mathrm{p}=0.002)$. However, the anticipated desertion by intimate partners $(\mathrm{AOR}=0.539 ; \mathrm{p}=0.086)$ and the anticipated segregation by the community $(\mathrm{AOR}=$ $0.0 .538 ; \mathrm{p}=0.076$ ) were not statistically significant predictors. These findings established that the study participants who anticipated negative consequences from their intimate partners and social support networks were not likely to disclose their HIV seropositive status. These findings further established that there was an inverse relationship between anticipated stigma and discrimination and self-disclosure of HIV seropositive status among PLWHA. This implies that anticipated stigma and 
discrimination promoted the non-disclosure of HIV seropositive status instead of fostering disclosure. The study concluded that anticipated stigma and discrimination against PLWHA act as risk factors for non-disclosure of HIV seropositive status thereby putting intimate partners and significant others at risk of HIV infection.

\section{APA CITATION}

Ngige, L., \& Ndayala, P. (2020). Effects of Anticipated Stigma and Discrimination on Self-Disclosure of HIV Seropositive Status among People Living with HIV and AIDS in Kenya. East African Journal of Health and Science, 2(1), 51-61. https://doi.org/10.37284/eajhs.2.1.211.

\section{CHICAGO CITATION}

Ngige, Lucy, and Phoebe Ndayala. 2020. "Effects of Anticipated Stigma and Discrimination on Self-Disclosure of HIV Seropositive Status among People Living with HIV and AIDS in Kenya". East African Journal of Health and Science 2 (1), 5161. https://doi.org/10.37284/eajhs.2.1.211.

\section{HARVARD CITATION}

Ngige, L. and Ndayala, P. (2020) "Effects of Anticipated Stigma and Discrimination on Self-Disclosure of HIV Seropositive Status among People Living with HIV and AIDS in Kenya", East African Journal of Health and Science, 2(1), pp. 51-61. doi: 10.37284/eajhs.2.1.211.

\section{IEEE CITATION}

L. Ngige and P. Ndayala, "Effects of Anticipated Stigma and Discrimination on Self-Disclosure of HIV Seropositive Status among People Living with HIV and AIDS in Kenya", EAJHS, vol. 2, no. 1, pp. 51-61, Sep. 2020.

\section{MLA CITATION}

Ngige, Lucy, and Phoebe Ndayala. "Effects of Anticipated Stigma and Discrimination on Self-Disclosure of HIV Seropositive Status among People Living with HIV and AIDS in Kenya". East African Journal of Health and Science, Vol. 2, no. 1, September 2020, pp. 51-61, doi:10.37284/eajhs.2.1.211.

\section{INTRODUCTION}

Statistics show that an estimated 1.6 million people are living with HIV in Kenya (UNAIDS, 2018). Despite knowing their HIV positive status, literature shows that a large proportion of PLWHA engage in unprotected sex with HIV negative partners or partners of unknown status putting them at risk of getting infected (Sarna et al., 2009). Interventions for PLWHA have mainly focused on their medical needs with little focus being given to the role of their self-disclosure on the overall health and psychological well-being of PLWHA and that of their intimate partners. In Kenya, $6 \%$ of couples are in discordant relationships (Kenya National Bureau of Statistics [KNBS] and ICF Macro (2010), while $45 \%$ have a partner who is HIV negative (National AIDS \& STI Control Programme [NASCOP], 2007). Seropositive disclosure rates to intimate partners have remained low. According to a study by Sarna et al. (2009), only $37 \%$ of the respondents disclosed their HIV status, while in the Kenya AIDS Indicator Survey
[KAIS] (2007) $35 \%$ of the PLWHA had disclosed their HIV status to their intimate partners in the year prior to the study (NASCOP, 2007). The lack of knowledge of HIV seropositive status of intimate partners increases the risk of HIV infection in the general population. Most PLWHA in Kenya have access to HIV treatment thus translating into fewer AIDS-related deaths and an increase in longevity of PLWHA (UNAIDS, 2020). Kenya represents one of the many African nations with an AIDS epidemic that is mainly heterosexually transmitted. Results show that $6.3 \%$ of Kenyan adults aged $15-49$ are infected with HIV; with a prevalence of $8.4 \%$ for females and $5.4 \%$ for males. Nairobi has the second-highest HIV prevalence rate of $7 \%$ after Nyanza (KNBS \& ICF Macro, 2010). Cultural stigma and taboos related to sex, increase PLWHA inability to disclose their HIV status. Nondisclosure to intimate partners has been an area of concern for health professionals and puts others at risk of infection. 


\section{Stigma and Discrimination against PLWHA}

UNAIDS (2003) defines HIV-related stigma and discrimination as a process of devaluation of people either living with or associated with HIV and AIDS. Discrimination follows stigma and is the unfair and unjust treatment of an individual based on his or her real or perceived HIV status. According to Heijnders et al. (2006) and Ogden and Nylade (2020), stigma and discrimination operate at multiple levels throughout society: within individuals, families, communities, institutions, media and government policies and practices. Stigma manifests itself in several ways which can be grouped as physical and social isolation or exclusion, verbal stigma, gossip, insults, loss of role, denial of religious and cultural rites, loss of respect, and loss of resources such as loss of jobs, customers, housing and health care services. Stigma has been identified as a barrier to health care, social support, and disclosure of HIV positive status diagnosis (Letteney \& Laporte, 2004; Campbell, 2005). Furthermore, the fear of HIV, stigmatisation and discrimination complicates decisions about testing, disclosure of HIV status, and ability to negotiate HIV preventive behaviours (WHO, 2008).

According to UNAIDS (2020), Nyblade et al. (2019) and Kalichman et al. (2005), the fear of stigma and discrimination implies that people are less likely to go for HIV testing, to disclose their HIV status to others, to adopt HIV preventive behaviour, or to access treatment, care and support. Stigmatising beliefs perpetuate the notion that HIV only happens to some individuals and not to others which may keep people away from HIV testing. PLWHA may suffer social rejection, financial insecurity, shame, guilt, low self-esteem, depression and other psychological problems. Those who perceive a stigmatising environment may be reluctant to or even afraid of disclosing their HIV serostatus to others, thereby putting their intimate partners and significant others at risk. According to Simbayi et al. (2007), Wolfe et al. (2006) and Liu et al. (2006) stigma and discrimination adversely affect disclosure to intimate partners, health care providers and family members. These researchers found an association between stigma and discrimination with postponing or rejecting medical care, non-adherence to anti- retroviral (ARV) and forced relocation of PLWHA outside their local communities for medical care because of fear of breaches of confidentiality by regular health care providers.

Studies done by Ogden and Nyblade (2005) revealed that women tend to experience greater stigma and discrimination compared to their male counterparts and they are more likely to experience it in the harshest and most damaging forms. Women are also disadvantaged in that they have fewer resources for coping with HIV. PLWHA are exposed to stigma and are considered the "reservoir" which breeds and passes on the virus to their intimate partners and other social support groups. According to Wiener et al. (2007), public and religious discourses on HIV and AIDS are of the view that the disease is a consequence of wanton and wild promiscuity associated with permissiveness and moral decadence. The anticipation of negative reactions and internalisation of stigma acts as barriers to HIV status disclosure (Medley et al., 2004; Gretchen et al., 2001). These complex phenomena might prevent persons from disclosing their seropositive status and the fear of negative consequences may prevent persons at risk from seeking Voluntary Counselling and Testing (VCT) services.

\section{Self-Disclosure of HIV Seropositive Status}

Studies show that majority of people with a positive HIV diagnosis are not likely to disclose their status to significant others. In a study by Arthur et al. (2020) on behaviour change in clients of health centre based VCT services in Kenya, results showed that there were high rates of disclosure by HIV negative clients but low rates for HIV positive clients. Prior to receiving results, $93 \%$ of the respondents had planned to disclose if HIV positive but at subsequent follow-up sessions, only $55 \%$ of HIV positives and $85 \%$ of HIV negatives had disclosed their HIV status. A study conducted by Daniel and Oladapo (2004) in Nigeria, to assess the factors associated with self-disclosure of HIV status to intimate partners among PLWHA reported that $67.8 \%$ of the respondents had disclosed their HIV positive status to their intimate partners. A study done by Kim et al. (2007) on assessing the factors correlated with disclosure of HIV infection in the Caribbean region reported that nearly one-third of 
the respondents had not disclosed their HIV seropositive status to anyone thereby putting others at risk of getting infected. This finding is contradicted by observations among the majority of pregnant mothers in Tanzania who were more likely to disclose their HIV positive status to a female relative than to a spouse (Gretchen et al., 2001).

There are gaps in knowledge of the effects of stigma and discrimination on self- disclosure of HIV seropositive status by PLWHA. Therefore, the purpose of the study was to examine the effects of anticipated stigma and discrimination among PLWHA and its effect on self-disclosure of HIV seropositive status to significant others within the proximal and distal social support networks. The objective of the study was to establish whether there was a statistically significant relationship between anticipated stigma and discrimination by significant others such as intimate partners and social support networks including family, friends, neighbours, workmates, religious affiliates and the local community and self-disclosure of HIV seropositive status by PLWHA. The objectives of the study were to establish whether anticipated stigma and discrimination predicted self-disclosure of HIV seropositive status by PLWHA. The null hypothesis posited that anticipated stigma and discrimination did not significantly predict self-disclosure of HIV seropositive status by PLWHA. The study was guided by Bronfenbrenner's (1979) ecological theory of human development and the consequence theory by Serovich (2001). These two theories take into consideration the individual's development as he or she interacts with the environment and the mental processes involved in the decision to disclose one's HIV seropositive status to social support networks such as spouse or intimate partners, family, friends, neighbours, religious group and workplace group.

\section{METHODOLOGY}

The survey was conducted among 232 randomly selected respondents who were HIV seropositive, knew their status and were registered in a community-based support group for PLWHA in Nairobi County, Kenya. A semi-structured questionnaire and focus group discussions were used to collect data on the perceptions of stigma and discrimination expected from intimate partners, family, friends, neighbours, local community, religious groups and workplace affiliates. The independent variables were represented by the anticipated stigma and discrimination from intimate partners and significant others in their social support networks. The participants responded to each item of the questionnaire using a three-point Likert scale ranging from "Agree (3-points) to Disagree (1-point)." The dependent variable was HIV seropositive status disclosure by PLWHA consisting of 15 items that measured the likelihood of self-disclosure of HIV seropositive status to intimate partners and to significant others in the social support networks. The reliability of the data collection instrument was established by the use of split-half Cronbach's reliability test. The Cronbach alpha measure of internal consistency ranged from .70 to .82 for all items. Ethical approvals were obtained from the relevant authorities and informed written consent was granted by the research participants prior to the commencement of the study.

\section{RESULTS}

Results revealed that $72.6 \%$ of the respondents were females and $27.4 \%$ were males. Results of the prevalence of HIV status disclosure by PLWHA to intimate partners and social support networks are presented in Table 1.

Table 1: Prevalence of HIV Seropositive Status Disclosure by PLWHA

\begin{tabular}{lll}
\hline HIV status disclosure & Frequency & Percentage (\%) \\
\hline HIV Status Disclosure by Gender & & \\
Males (N=65) & 28 & 43.1 \\
HIV Status Disclosure & 37 & 53.6 \\
HIV Status Non-disclosure & & \\
Females (N=167) & 89 & 53.3 \\
HIV Status Disclosure &
\end{tabular}




\begin{tabular}{lll}
\hline HIV status disclosure & Frequency & Percentage (\%) \\
\hline HIV Status Non-disclosure & 78 & 46.7 \\
HIV self-disclosure to intimate partners (N=232) & & \\
HIV status self-disclosure to intimate partners & 117 & 50.5 \\
HIV status non-disclosure to intimate partners & 115 & 49.5 \\
HIV self-disclosure to social support networks* & & \\
Health care providers/Counselors & 133 & 62.1 \\
Friends & 94 & 43.9 \\
Family & 65 & 28.0 \\
Religious leaders & 41 & 19.2 \\
Teachers & 30 & 12.9 \\
Neighbours & 25 & 11.7 \\
\hline
\end{tabular}

*Multiple responses included

The results presented showed that about half $(50.5 \%)$ of the respondents had disclosed their HIV seropositive status while $49.5 \%$ had not. It was observed that females were more likely to disclose their HIV status $(53.3 \%)$ than their male counterparts $(43.1 \%)$. This could be attributed to the greater need of females to access medical and financial support from their significant others which necessitated HIV status self-disclosure. With reference to significant others, the results revealed that about two-thirds $(62.1 \%)$ of the respondents had disclosed their HIV seropositive status to a health care provider or counsellor, $44 \%$ to a friend, $19.2 \%$ to a religious leader, $12.9 \%$ to a teacher and $11.7 \%$ to a neighbour. These findings imply that majority of PLWHA in the study area were more likely to disclose their HIV status to a health care provider or counsellor than to other social support networks.

The results from the focus group discussions showed that the health care personnel provided them with medication and psychological support needed to deal with their condition than any other group. The PLWHA felt that health professionals would not stigmatise or discriminate against them because as health care providers they had an obligation to maintain the confidentiality of their patients (clients). Results further indicated that while most of the PLWHA reported strong religious affiliations in the FGDs, only $19.2 \%$ of them had disclosed to a religious leader. The respondents were of the opinion that religious leaders were less supportive of PLWHA. On further probing, most respondents reported that they had disclosed their HIV seropositive status to teachers only in extraneous circumstances such as to explain why they had delayed in school fees payment or to explain the constant absenteeism of their children from school. Disclosure to neighbours was done to enlist support such as being taken to hospital or being helped with household daily chores when they were unable to perform their activities of daily living.

\section{Anticipated stigma and discrimination among PLWHA}

The anticipated consequences of self-disclosure of HIV seropositive status by PLWHA were important as they determined to a large extent the outcome of the decision on whether or not to disclose their HIV serostatus to intimate partners and social support networks. Results showing the distribution of anticipated stigma and discrimination from the proximal social support networks such as intimate partners, family and friends are presented in Table 2.

Table 2: Distribution of Anticipated Stigma and Discrimination among PLWHA from the proximal social support networks

\begin{tabular}{lll}
\hline Anticipated stigma and discrimination & Frequency & Percentage (\%) \\
\hline Intimate partner-based stigma and discrimination & & \\
Malicious gossip & 129 & 55.6 \\
Emotional violence & 147 & 63.3 \\
\hline
\end{tabular}


East African Journal of Health and Science, Volume 2, Issue 1, 2020

Article DOI: https://doi.org/10.37284/eajhs.2.1.211

\begin{tabular}{lll}
\hline Anticipated stigma and discrimination & Frequency & Percentage (\%) \\
\hline Physical violence & 149 & 64.3 \\
Denial of conjugal rights & 112 & 48.3 \\
Desertion or divorce by the spouse & 161 & 69.4 \\
& & \\
Family-based stigma and discrimination & 43 & 18.5 \\
Physical abuse & 82 & 35.3 \\
Denial of financial support & 128 & 55.1 \\
Exclusion from family activities & 128 & 55.1 \\
Isolation from family functions & 118 & 50.9 \\
Abandonment by family & & \\
& & \\
Friends' based stigma and discrimination & 156 & 67.3 \\
Malicious gossip by friends & 160 & 68.9 \\
Denial of financial support & 135 & 58.2 \\
Friends not sharing anything with PLWHA & 123 & 57.4 \\
Exclusion from friends' functions & 137 & 59.0 \\
Termination of friendship &
\end{tabular}

Multiple responses included

The results presented in Table 2 demonstrated that participants anticipated negative outcomes from their spouses or intimate partners, family and friends network following self-disclosure of HIV seropositive status. More than half of the respondents anticipated malicious gossip from their intimate partners, about two-thirds (63.3\%) anticipated intimate partner emotional violence 64.3\%anticipated physical violence, $48.3 \%$ anticipated denial of conjugal rights and $69.4 \%$ expected desertion or divorce by their spouses. In terms of the close family unit, respondents anticipated physical abuse (18.5\%), denial of financial support (35.3\%), exclusion from family activities and isolation from family social functions $(55.1 \%)$ respectively and about half $(50.9 \%)$ anticipated abandonment by their families. Results revealed that the respondents anticipated negative consequences from friends after self-disclosure of HIV seropositive status diagnosis. These ranged from malicious gossip (67.3\%) to termination of friendship (59.0\%).

The study sought to investigate the anticipated reactions from the distal social support networks such as the neighbours, local community, religious group and the workplace affiliates. The results are presented in Table 3.

Table 3: Distribution of Anticipated Stigma and Discrimination among PLWHA from the distal social support networks

\begin{tabular}{lll}
\hline Variable & Frequency & Percentage (\%) \\
\hline Community-based stigma and discrimination & & \\
Avoidance of physical contact with PLWHA & 144 & 63.6 \\
Exclusion from community functions & 158 & 68.4 \\
Maltreatment of children of PLWHA & 154 & 66.7 \\
Denial of access to community amenities & 71 & $30 . .8$ \\
Segregation by the community & 150 & 64.9 \\
Religious based stigma and discrimination & & \\
Malicious gossip & 116 & 50.0 \\
Isolation from home-based fellowship activities & 94 & 40.5 \\
Denial of religious leadership positions & 149 & 64.3 \\
Exclusion from religious functions & 107 & 46.7 \\
Excommunication from the religious group & 61 & 26.9 \\
\hline
\end{tabular}




\begin{tabular}{lll}
\hline Variable & Frequency & Percentage (\%) \\
\hline Workplace-based stigma and discrimination & & \\
Isolation at the workplace & 114 & 57.3 \\
Lack of medical support & 130 & 65.3 \\
Demotion at work & 117 & 58.8 \\
Forced early retirement & 115 & 58.1 \\
Dismissal from work & 131 & 65.8 \\
\hline
\end{tabular}

*Multiple responses included

Results revealed that respondents anticipated stigma and discrimination from their local community such as avoidance of physical contact (63.6\%), exclusion from community functions such as weddings $(68.4 \%)$, maltreatment of their children (66.7\%), and denial of access to community amenities such as boreholes $(64.9 \%)$ to segregation by the community. Likewise, respondents anticipated that the religious group would spread malicious gossip (50.0\%), prohibit respondents from attending home-based fellowship activities $(40.5 \%)$, denial of leadership positions (64.3\%), exclusion from religious functions such as weekly worship meetings (46.7\%) and more than one-fourth anticipated excommunication from the religious group (26.9). In terms of the workplace dynamics, respondents anticipated isolation by their colleagues (57.3\%), denial of medical support by the employer $(65.3 \%)$, demotion at work $(58.8 \%)$, forced early retirement $(58.1 \%)$ and dismissal from work $(65.8 \%)$.

\section{Hypothesis Test Results}

The null hypothesis posited that anticipated stigma and discrimination by the social support networks did not significantly predict self-disclosure of HIV seropositive status by PLWHA. The results of the binary logistic regression are presented in Table 4.

Table 4: Predictors of Self-Disclosure of HIV Seropositive Status among PLWHA

\begin{tabular}{llll}
\hline Variable & $\begin{array}{l}\text { Adjusted } \\
\text { Odds Ratio } \\
\text { (AOR) }\end{array}$ & $\begin{array}{l}\text { Significance } \\
\text { (p-value) }\end{array}$ & $\begin{array}{l}\mathbf{9 5 \%} \\
\text { Confidence } \\
\text { Interval }\end{array}$ \\
\hline Intimate partner violence & 0.635 & $0.016^{*}$ & $0.439-0.919$ \\
Desertion by intimate partner & 0.539 & 0.086 & $0.272-1.066$ \\
Abandonment by family & 0.410 & $0.002^{*}$ & $0.235-0.715$ \\
Isolation by friends & 0.136 & $0.001^{*}$ & $0.041-0.454$ \\
Exclusion from social functions & 0.365 & $0.002^{*}$ & $0.192-0.964$ \\
Exclusion from access to community amenities & 0.416 & $0.032^{*}$ & $0.187-0.928$ \\
Segregation by the community & 0.538 & 0.076 & $0.270-1.064$ \\
Exclusion from religious group & 0.446 & $0.032^{*}$ & $0.213-0.931$ \\
Dismissal from the workplace & 0.266 & $0.002^{*}$ & $0.152-5.185$ \\
\hline
\end{tabular}

*significant predictors at $\mathrm{p} \leq 0.05$

The results revealed that anticipated stigma and discrimination by intimate partners were_negative predictors of self-disclosure of HIV seropositive status among PLWHA as evidenced by the Adjusted Odds Ratio (AOR < 1.000). The statistically significant negative predictors included anticipated intimate partner violence $(\mathrm{AOR}=0.635$; $\mathrm{p}=0.016)$ and abandonment by the family $(\mathrm{AOR}=$ $0.410 ; \mathrm{p}=0.002)$. However, the anticipated desertion by intimate partners $(\mathrm{AOR}=0.539 ; \mathrm{p}=$
0.086) was negative, but it was not statistically significant. These findings indicate that the study participants who anticipated negative consequences from their intimate partners were not likely to disclose their HIV seropositive status. The results further showed that anticipated stigma and discrimination by social support networks were negative predictors of self-disclosure of HIV seropositive status among PLWHA as evidenced by the Adjusted Odds Ratio (AOR < 1.000). The 
statistically significant negative predictors included anticipated isolation by friends $(\mathrm{AOR}=0.136$; $\mathrm{p}=0.001$ ), exclusion from social functions $(\mathrm{AOR}=$ $0.365 ; \mathrm{p}=0.002)$, exclusion from access to community amenities $(\mathrm{AOR}=0.416 ; \mathrm{p}=0.032)$, exclusion by the religious group $(\mathrm{AOR}=0.446 ; \mathrm{p}=$ $0.032)$, and dismissal from the workplace $(\mathrm{AOR}=$ $0.266 ; \mathrm{p}=0.002)$. However, the anticipated segregation by the community $(\mathrm{AOR}=0.0 .538 ; \mathrm{p}=$ 0.076 ) was negative, but it was not statistically significant. These findings established that there was an inverse relationship between anticipated stigma and discrimination and self-disclosure of HIV seropositive status among PLWHA. This implies that anticipated stigma and discrimination promoted the non-disclosure of HIV status instead of fostering disclosure. The hypothesis stating that anticipated stigma and discrimination from social support networks did not significantly predict selfdisclosure of HIV seropositive status by PLWHA was therefore rejected.

\section{DISCUSSION}

The research findings demonstrated that anticipated stigma and discrimination by the social support networks were significant negative predictors of self-disclosure of HIV seropositive status by PLWHA. Findings revealed that there were high levels of anticipated stigma and discrimination in all social support contexts. Self-disclosure of HIV seropositive status was associated with negative psychosocial effects such as stigma and discrimination by intimate partners, family, friends, religious group, neighbours, community members and colleagues at the workplace. The higher the levels of anticipated stigma and discrimination from the social support structures the less likely the respondents were to disclose their HIV seropositive status to their intimate partners and social support networks. These findings concur with previous studies by Sarna et al. (2009) and NASCOP (2007) which reported that non-disclosure of HIV seropositive status diagnosis remains a health concern among PLWHA which may put intimate partners and significant others at risk of HIV infection. These findings are also supported by Maman et al. (2001) in a study in Tanzania which reported that self-disclosure of a positive HIV diagnosis to intimate partners was associated with anger, denial of sexual intimacy, physical violence, divorce, separation or desertion of PLWHA. Female respondents were more likely to forgive their intimate partners and continue with the relationship, while male respondents were more likely to abandon their spouses and sexual partners and remarry. These findings are consistent with a study by Simoni (2005) which revealed that if individuals believe a potential sex partner will respond with anger after HIV positive disclosure, they are probably less likely to reveal their HIV positive status.

Furthermore, Simbayi et al. (2007) reported that people who fail to disclose their HIV status may have had adverse experiences related to previous disclosures. This concurs with research by Ogden and Nylade (2020) which revealed that some families do not really know the extent or the manner of the risks they are exposed to by PLWHA and they generally fear getting infected. This creates anxiety and may result in the isolation and rejection of PLWHA by significant others, avoidance of their goods and services, and secondary stigmatisation against their children and other relatives. In addition, families are faced with mixed feelings towards HIV infected family members. These range from love, pity, care and support to hatred and abandonment or a combination of all these reactions. On one hand, community members feel that the PLWHA need support, but many feel that they should be segregated in order to protect the rest of the community from HIV infection. A study in China by Xiaobin et al. (2006) found out that relatives, friends and neighbours discriminated against PLWHA, for example by taking a detour to avoid their homes, refusing to visit or to help them, and refusing to eat food handled by them. Religion is a major social institution which is expected to provide unconditional support to all people. However, in the case of PLWHA, this is not always the case. A study assessing factors correlated with disclosure of HIV infection by Kim et al. (2007) in the Caribbean found that most Christian churches expressed conservative morals on sex, gender roles and HIV and AIDS, preventing infected individuals from seeking support from religious affiliates. However, these findings are contrary to a research conducted by Issiaka et al. (2001) in Tanzania which reported that while some PLWHA report negative outcomes from HIV status disclosure, in actual fact responses from social support networks 
are far more likely to be sympathetic and supportive.

\section{CONCLUSION}

This study has established that there was an inverse relationship between anticipated stigma and discrimination and self-disclosure of HIV seropositive status among PLWHA. This study has demonstrated that the respondents who anticipated negative consequences from their intimate partners and social support networks were not likely to disclose their HIV seropositive status t significant others. This implies that anticipated stigma and discrimination promoted the non-disclosure of HIV seropositive status instead of fostering disclosure. The study concluded that anticipated stigma and discrimination against PLWHA were risk factors for non-disclosure of HIV seropositive status thereby putting intimate partners and significant others at risk of HIV infection. There is, therefore, need to develop programmes for counselling of PLWHA on the management of anticipated stigma and discrimination, living positively, selfdisclosure and prevention of re-infection with HIV. This may help to reduce the self-stigma experienced by PLWHA thereby encouraging selfdisclosure of seropositive status to intimate partners and to significant others.

\section{ACKNOWLEDGEMENTS}

We wish to appreciate the support of the respondents who participated in this research.

\section{AUTHORS' CONTRIBUTIONS}

The first and second author participated in the research process from research conception to the development of research tools, data collection, analysis and writing of the research report.

\section{REFERENCES}

Arthur, G., Nduba, V., Forsythe, S., MutemiWangahu, R., Odhiambo, J., \& Franklin, C. (2020). Behaviour change in clients of health centre based voluntary HIV counseling and testing (VCT) services in Kenya. Retrieved 2 August, 2020 from http://sti.bmj.com/cgi/content/abstract/sti.

Bronfenbrenner, U., (1994). Ecological models of human development. International Encyclopedia of Education, 3 (2), 1643-1647.

Campbell, C. C., Foulis, A., Maimane, S. \& Sibiya, Z. (2005). "I Have an Evil Child at My House": Stigma and HIV and AIDS Management in a South African Community. American Journal of Public Health, 5 (5), 808-815.

Daniel, O. \& Oladapo O., (2004). Self-disclosure of HIV sero-status to sexual partners in Nigeria. Sexual Health Matters, 6, 38-40.

Gretchen, S., Fawzi, M., C. Kaaya, S., Mbwambo, J., Msamanga, G., Hunter, I., David, J. F. \& Wafaie, W. (2001). Predictors of HIV-1 serostatus disclosure: a prospective study among HIV-infected pregnant women in Dar es Salaam, Tanzania. Epidemiology \& social Aspects of AIDS 15 (14):1865-1874.

Issiaka, S., Cartoux, M., Ky-Zerbo, O., Meda, N., Dabis, F. \& Van de Perre, P. (2001). Living with HIV: Women's experience in Burkina Faso, West Africa. AIDS Care, 13 (1): 123-128.

Kenya National Bureau of Statistics (KNBS) \& ICF Macro, (2010). Kenya Demographic and Health Survey 2008-2009. Calverton, Maryland: KNBS and ICF Macro.

Heijnders, M., \& Van Der Meij, S. (2006). The fight against stigma: an overview of stigmareduction strategies and interventions. Psychology, health \& medicine, 11(3), 353363.

Kalichman, S. C., Rompa, D. \& M. Cage, M. (2005). Group intervention to reduce HIV transmission risk behavior among persons 
living with HIV and AIDS. Behavior Modification, 29 (2): 256-285.

Kim, B., France L., Remi S., Annie S., Bruno S. \& Dray-Spira, R. (2007). Factors Correlated with disclosure of HIV infections in the French Antilles and French Guiana: Results from the ANRS-ENRS-EN13-VESPA-DFA Study. AIDS, 21 (Suppl. 1), S89-S94.

Letteney, S., \& Laporte, H. H. (2004). Deconstructing stigma: perceptions of HIV seropositive mothers and their disclosure to children. Social Work in Health Care, 38 (3), 105-123.

Liu, H., Hu, Z., Li, X., Stanton, B., Naar-King, S., \& Yang, H. (2006). Understanding the interrelationships among HIV related stigma, concern about HIV infection, and intent to disclose HIV serostatus: a pretest-posttest study in rural area of Eastern China. AIDS Patient Care \& STDs, 20 (2), 133-142.

Maman, S. \& Medley A., (2004). Gender dimensions of HIV status disclosure to sexual partners: rates, barriers and outcomes. $A W H O$ review paper. Geneva: World Health Organisation.

Medley, A., Garcia-Moreno, C. \& Maman, S. (2004). Rates, barriers and outcomes of HIV serostatus disclosure among women in developing countries: implications for prevention of mother-to-child transmission programmes. Bull. World Health Organ. 82 (4), 299-307.

Nyblade, L., Stockton, M.A., Giger, K. Stigma in health facilities: why it matters and how we can change it. BMC Med 17, 25 (2019). https://doi.org/10.1186/s12916-019-1256-2.

National AIDS and STI Control Programme (NASCOP), Kenya, (2007). Kenya AIDS Indicator Survey (KAIS). Nairobi, Kenya.

Ogden, J. \& Nyblade, L. (2020). Common at its core: HIV-related stigma across contexts. Retrieved 8, August 2020 from https://www.icrw.org.
Population Council/Horizons (2001). HIV and Partner Violence: Implications for HIV Voluntary Counseling and Testing Programs. New York: The Population Council Inc.

Sarna, A., Chersich, M., Okal, J., Luchters, S., Mandaliya, K., Rutenberg, N. \& Temmerman, M., (2009). Changes in sexual risk taking with antiretroviral treatment: influence of context and gender norms in Mombasa, Kenya. Culture, Health and Sexuality: An International Journal for Research, Intervention and Care, 11 (8), 783-797.

Serovich, J. M., (2001). A Test of Two HIV Disclosure Theories. AIDS Education. PubMed articles 13 (4): 355-364.

Simbayi, L., Kalichman, S., Strebel, A., Cloete, A., Henda, N., \& Mqeketo, A., (2007). Disclosure of HIV status to sex partners and sexual risk behaviours among HIV positive men and women, Cape Town, South Africa. Sex Transmitted Infections, 83, 29-34.

Simoni, J.M., (2005). HIV disclosure and safe sex. In S. C. Kalichman (Ed.), Positive Prevention: Reducing HIV transmission among people living with HIV/AIDS, (65-98). New York: Springer.

UNAIDS (2003). Fact sheet on stigma and discrimination. Retrieved 17, August 2020 from https://unaids.org.

UNAIDS (2018). HIV and AIDS: Country Report Kenya. Retrieved 14, August 2020 from https://unaids.org.

UNAIDS (2020). Global AIDS Update-2020. Retrieved 14, August 2020 from https://unaids.org.

Wiener, L. S., Battles, H. B., Wood, L. V. (2007). A longitudinal study of adolescents with perinatally or transfusion acquired HIV infection: Sexual knowledge, risk reduction self-efficacy and sexual behavior. AIDS Behavior 11; 471 -478.

Wolfe, W.R., Weiser, S.D., Bangsberg, D.R. (2006). Effects of HIV related stigma among an early sample of patients receiving antiretroviral 
East African Journal of Health and Science, Volume 2, Issue 1, 2020

Article DOI: https://doi.org/10.37284/eajhs.2.1.211

therapy in Botswana. AIDS Care, 18 (8), 931933.

World Health Organization (2008). 'Towards Universal Access: Scaling up priority HIV and AIDS interventions in the health sector: Progress report. Geneva: WHO.

Xiaobin C., Sheena, G., Jie, X. \& Zunyou, W., (2006). Understanding HIV-Related Stigma and Discrimination in a "Blameless" Population. AIDS Education and Prevention, 18 (6), 518-528. 